\title{
Neurological Bulletin
}

FEATURING ARTICLES BY TRAINEES IN NEUROLOGY \& NEUROSCIENCE

\section{Xanthomatous Hypophysitis: An Unusual Case of a Sellar Mass}

\author{
Andrea V. Haas and Thomas W. Smith \\ University of Massachusetts Medical School, Worcester, MA
}

\section{The Case}

The patient is a 57 year-old man with hypertension, who initially presented to his primary care doctor complaining of impotence and fatigue of two months' duration. Laboratory values taken at the visit showed a decreased testosterone level of $9 \mathrm{ng} / \mathrm{dl}$ (reference 180740), a low free $\mathrm{T} 4$ of $0.56 \mathrm{ng} / \mathrm{dl}$ (reference 0.7-1.5), and a normal TSH of $1.06 \mathrm{mIU} / \mathrm{L}$. He was referred for an endocrine evaluation and seen one week later. At the endocrinologist's office, the patient denied additional symptoms of headaches and polyuria. Visual fields and cranial nerves II-XII were otherwise grossly intact. Additional laboratory studies showed abnormal values of a low afternoon cortisol of $2 \mathrm{mcg} / \mathrm{dl}$ (reference 3-12) that increased to 11 after Cortrosyn, a low LH of $0.8 \mathrm{mIU} / \mathrm{ml}$ (reference 2-18), and a low serum testosterone of $3 \mathrm{ng} / \mathrm{dl}$, but normal values for serum potassium, creatinine, prolactin, sodium, and FSH. He was subsequently started on hydrocortisone $10 \mathrm{mg}$, levothyroxine $0.10 \mathrm{mg}$, and testosterone 5 mg patches, all once a day, and scheduled for an MRI of the brain.

MRI of the brain showed a $13 \mathrm{~mm}$ mass present in the sella extending superiorly into the suprasellar cistern and impressing the inferior margin of the optic chiasm (Figure 1). The mass appeared homogenous, wellcircumscribed, and demonstrated no enhancement on post-contrast imaging. The initial differential diagnosis was atypical pituitary macroadenoma, craniopharyngioma, or Rathke's cleft cyst.

The patient had a formal neuroophthalmologic evaluation that demonstrated intact visual fields. He was evaluated by a neurosurgeon who counseled the patient on the options of watchful waiting versus proceeding with transsphenoidal craniectomy. The patient opted to defer surgery and so was scheduled for a follow-up MRI in 6 months time.

On subsequent MRI, the pituitary mass had increased in size from $13 \mathrm{~mm}$ to $17 \mathrm{~mm}$ and the signal intensity within the lesion had diminished on T-1 sequences, suggesting that there may have been hemorrhage into the mass since the earlier study (Figure 2). There was a ring of enhancement around the periphery of the lesion and a central portion that did not enhance, consistent with a cystic tumor. The optic chiasm was further elevated.

Correspondence to Andrea V Haas: andrea.haas@umassmed.edu

Keywords: Xanthomatous Hypophysitis, pituitary disease, sella mass, diabetes insipidus, hypogonadism 

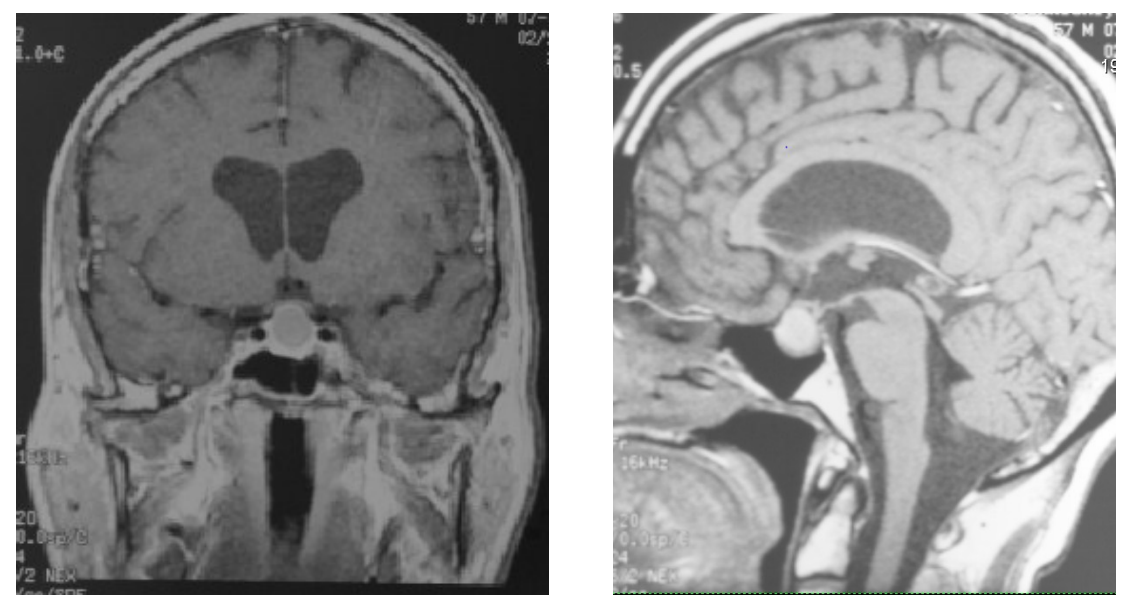

Figure 1: Initial (left) coronal and (right) sagittal T-1 MRI, demonstrating a $13 \mathrm{~mm}$ sellar mass.

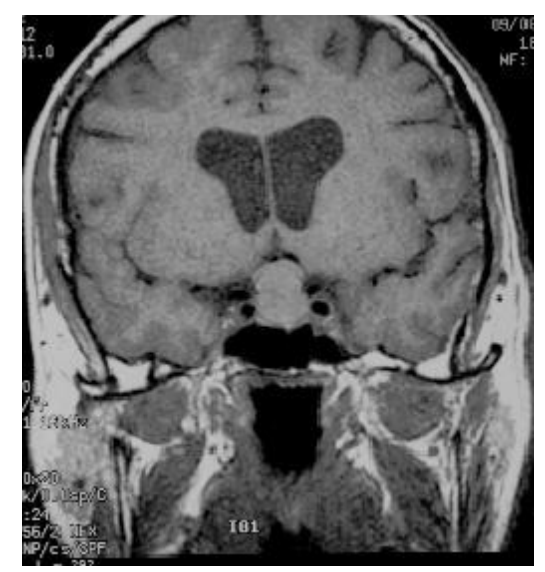

Figure 2: Follow-up T-1 MRI demonstrating growth of the sellar mass from $13 \mathrm{~mm}$ to $17 \mathrm{~mm}$.

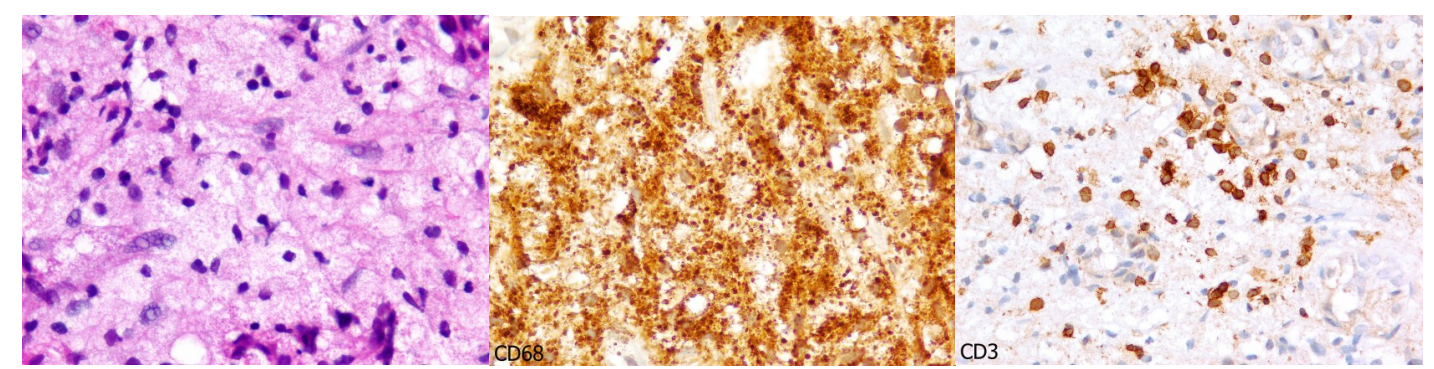

a.

b.

c.

Figure 3: a. Pathology demonstrated the anterior pituitary infiltrated by foamy histiocytes. b. Histiocytes were confirmed by positive CD68 staining. c. Reactive T-lymphocytes were also present, staining for CD3. 
Neurol. Bull. 4: 41-44, 2012

doi:10.7191/neurol_bull.2012.1034

The patient was starting to note some loss of vision, and with the increase in the size of the mass, the patient underwent transsphenoidal resection of his mass. During the operative resection of the mass, thick yellow fluid emerged. Pathology of the mass was consistent with xanthomatous hypophysitis. The specimen demonstrated sheets of foamy histiocytes, confirmed by immunohistochemistry as positive for the macrophage marker CD68, some trapped normal pituitary acini, and scattered reactive $\mathrm{T}$ lymphocytes (Figure $3)$.

After surgery, the patient's vision improved, and he reported only some scant yellow mucous nasal drainage. However, on follow-up evaluation shortly after surgery, the patient complained of having to awaken at least four times nightly to urinate, a difficulty he reported as having started at least one week prior to surgery. Serum osmolality was 305 $\mathrm{mOsm} / \mathrm{kg}$ (reference 275-295) and urine osmolality 253. A simultaneous antidiuretic hormone level was undetectable and he was begun on $0.05 \mathrm{mg}$ DDAVP by mouth twice daily for his diagnosis of diabetes insipidus (DI). Given that the patient reported that symptoms began prior to surgery, his DI is most likely a result of the hypophysits rather than a complication of surgery.

Six months after surgery, the patient was feeling well. He remained on the same medical regimen of hydrocortisone $10 \mathrm{mg}$ qAM and $5 \mathrm{mg}$ qPM, levothyroxine $0.1 \mathrm{mg}$ daily, testosterone $5 \mathrm{mg}$ patch daily, and DDAVP $0.05 \mathrm{mg}$ twice daily. Follow-up MRI showed normal appearance to the pituitary stalk, complete resection of the mass and no evidence of recurrence.

\section{Background}

Xanthomatous hypophysitis is an inflammatory disorder of the pituitary gland character- ized by infiltration of lipid-laden histiocytes, also known as xanthoma cells. While xanthomatous hypophysitis is an extremely uncommon cause of pituitary dysfunction, it is one of the possible causes of a non-hormone secreting mass of the sella turcica. Xanthomatous hypophysitis was first reported in 1998 and only a handful of cases have been described since then in the literature ${ }^{1}$. The cause of xanthomatous hypophysitis remains unknown, with infectious, autoimmune, and localized endothelial dysfunction etiologies each having been postulated ${ }^{1-3}$. The average age at diagnosis is 37 , with a $3: 1$ predominance of females to males ${ }^{3}$.

Xanthomatous hypophysitis commonly presents with headache and decreased libido. Hypogonadism has been present in nearly all reported cases. The visual disturbances and DI found in our patient are uncommon ${ }^{1}$, since most cases of xanthomatous hypophysitis are confined to the anterior pituitary without alteration of the stalk or optic chiasm $^{1}$. However, DI has been described in three previous cases of xanthomatous hypophysitis $^{1,4,5}$. Therefore, xanthomatous hypophysitis should be more routinely included when considering etiologies of DI. The genesis of DI in xanthomatous hypophysitis is poorly understood, but in this particular case might result from either inflammatory infiltration of the pituitary stalk or from compression of the pituitary stalk ${ }^{4}$.

MR imaging is the best modality for evaluation of sellar masses. On T1-weighted images, most cases of xanthomatous hypophysitis appear as a symmetric enlargement of the pituitary gland with round cystic lesions ${ }^{2}$. Reports of xanthomatous hypophysitis have shown a more cystic appearance than other types of hypophysitis. If MRI demonstrates an enlarged pituitary gland, a cystic portion of the mass, and accompanying symptoms of hypogonadism, xanthomatous hypophysitis 
should be considered one of the likely causes $^{6}$. Diagnosis cannot be confirmed until the time of surgery with pathological evaluation of the resected pituitary tissue. Pathology demonstrates mixed cell infiltrates of foamy histiocytes and mature lymphocytes and contains cyst-like areas typically confined to the anterior pituitary ${ }^{2}$.

Both medical and surgical treatments have been attempted. Steroids have been found to be largely ineffective in the management of xanthomatous hypophysitis, unlike their utility in lymphocytic hypophysitis ${ }^{4}$. Consequently, surgical resection is recommended in almost all cases both to alleviate symptoms and to confirm the diagnosis. Overall, xanthomatous hypophysitis has a relatively good prognosis: more than $50 \%$ of patients recover pituitary function after transsphenoidal surgery. In those cases where pituitary function does not improve, it is believed that chronic pituitary inflammation may have led to fibrosis and permanent hypopituitarism ${ }^{7}$.

This case supports that xanthomatous hypophysitis deserves more consistent consideration in the differential diagnosis of sella masses capable of causing both DI and visual impairment.

\section{References}

1. Aste L, Bellinzona M, Meleddu V, Farci G, Manieli C, Godano U. Xanthomatous hypophysitis mimicking a pituitary adenoma: case report and review of the literature. J Oncol 2010:195323, http:// dx.doi.org/10.1155/2010/195323

2. Burt MG, Morey AL, Turner JJ, Pell M, Sheehy JP, Ho KK. Xanthomatous pituitary lesions: a report of two cases and review of the literature. Pituitary 2003;6:161 -168 , http://dx.doi.org/10.1023/
B:PITU.0000011177.43408.56

3. Leporati P, Landek-Salgado MA, Lupi I, Chiovato L, Caturegli P. IgG4-related hypophysitis: a new addition to the hypophysitis spectrum. J Clin Endocrinol Metab 2011;96:1971-1980, http:// dx.doi.org/10.1210/jc.2010-2970

4. Gutenberg A, Hans V, Puchner MJ, et al. Primary hypophysitis: clinicalpathological correlations. Eur J Endocrinol 2006;155:101-107, http:// dx.doi.org/10.1530/eje.1.02183

5. Deodhare SS, Bilbao JM, Kovacs K, et al. Xanthomatous Hypophysitis: A novel entity of obscure etiology. Endocr Pathol 1999;10:237-241, http:// dx.doi.org/10.1007/BF02738885

6. Jang SJ, Kim EJ, Choi WS, Park BJ. Xanthomatous hypophysitis: a case report and literature review. J Korean Soc Radiol 2011;64:297-301.

7. Tashiro T, Sano T, Xu B, et al. Spectrum of different types of hypophysitis: a clinicopathologic study of hypophysitis in 31 cases. Endocr Pathol 2002;13:183-195, http://dx.doi.org/10.1385/EP:13:3:183

Disclosure: the authors report no conflicts of interest.

All content in Neurological Bulletin, unless otherwise noted, is licensed under a Creative Commons Attribution-Noncommercial-Share Alike License http://creativecommons.org/licenses/by-nc-sa/3.0/ (ISSN 1942-4043) 